\title{
CAIOZZI TRAS LA HUELLA DE DONOSO: LA PLASMACIÓN DEL AMBIENTE AJADO EN CORONACIÓN \\ UNA REVISIÓN A LAS RELACIONES ENTRE CINE Y LITERATURA A PARTIR DE UN CASO CHILENO
}

\author{
CAIOZZI FOLLOWING DONOSO'S TRAIL: THE WORN-OUT \\ SETTING EMBODIMENT IN CORONACIÓN \\ A REVISION OF THE RELATIONSHIPS BETWEEN FILM AND \\ LITERATURE BASED ON A CHILEAN CASE
}

Silvia Margarita Donoso ${ }^{1}$

Resumen: Este artículo aborda los vínculos entre la literatura y el cine a partir de la estrecha relación entre el cineasta Silvio Caiozzi y el escritor José Donoso. El análisis se centra en Coronación, novela de Donoso de 1957, filme de Caiozzi de 2000. Sobre la novela, se revisa el problema de la decadencia de una clase social que experimenta el ocaso y la inanidad de un individuo asentado en ella. A partir de una reflexión teórica sobre las relaciones entre la literatura y el cine, se observa cómo, luego, operan los aspectos propios de la novela en el trabajo fílmico que realiza Caiozzi, verificando que allí estos elementos se manifiestan casi exclusivamente a través de un tratamiento visual de los ambientes y de las pasiones de los personajes. Se destaca el énfasis en el universo extra-verbal que imprime el cineasta a su filme.

Palabras clave: Coronación; cine; literatura.

Abstract:This article addresses the link between literature and film, stemming from the close relationship between Silvio Caiozzi, filmmaker, and the writer Jose Donoso. The analysis focuses on Coronación, Donoso's 1957 novel, Caiozzi's film in 2000. Regarding the novel, we review the problem of the decline of a social class in its twilight and the inanity of the individual settled within it. From a theoretical reflection between film and literature, we observe the novel's own aspects operating in Caiozzi's filmmaking, verifying that

1 Doutora pela Universidade de Lisboa, Portugal. Professora na Pontifica Universidad Católica de Valparaíso, Chile. 
these elements are manifested almost exclusively through the visual treatment of the settings and the characters' passions, with a noted emphasis on the extra-verbal universe that the filmmaker imprints on his film.

Keywords: Coronación; film; literature.

\section{Coronación de José Donoso, lo decadente y lo anodino}

Coronación, de 1957, tiene una posición particular dentro de la narrativa de José Donoso (Chile, Premio Nacional de Literatura 1990), pues es su primera novela y en ella está la génesis de las temáticas que desarrollará a lo largo de muchas de sus obras, todas relacionadas de una u otra manera con el individuo alienado, desajustado y que raya en lo patético. SHAW (1999) será claro al referirse al contenido de las obras del narrador chileno: "El gran tema de Donoso, en todas sus obras, es la desintegración: la del individuo (y de la familia, el núcleo social), la de la sociedad [...] y la del sistema de valores y creencias en que se fundamentaba tradicionalmente la vida individual y social" (176-177). Es importante señalar que esa desintegración aludida por el crítico no opera solo a nivel de la clase alta que siempre figura en las novelas donosianas, sino también a nivel de todo individuo que vive bajo condiciones excesivas: de abundancia o de carencia. Por ello permanentemente en las historias de este narrador chileno aparecen ricos y pobres; escasamente circulan por sus letras personajes que no tengan ni apremios económicos ni una vida exageradamente holgada.

En Coronación, el tópico de la decadencia solo es aplicable a la abuela, Elisita Grey de Ábalos, por razones bastante indudables: solo ella puede vanagloriarse de un pasado esplendoroso, alimentarse de recuerdos de una época majestuosa, en que era una suerte de "reina". Sus empleadas, Rosario y Lourdes, han sido testigos de ello y por esta razón la coronan. Al recordar la anciana su vida pasada, es claro que en esta había un panorama sembrado de aspectos que han dejado de ser relevantes, tales como el apellido, la ascendencia familiar, las convenciones sociales inapelables, etc.; elementos evocados por ella con nostalgia al observar que en la actualidad de los años ' 50 todo esto se ha desbaratado. Un pasaje importante en que está sermoneando a Estela, quien cuida de ella, identifica íntegramente esas añoranzas de la anciana:

Me acuerdo cuando vivíamos en el Cerro Alegre, en Valparaíso, y mi papá nos llevaba a la Filarmónica. Iba toda la mejor gente, y muy elegante, las señoras con sus alhajas y sus 
lindos escotes, los caballeros de pechera dura. Daba gusto. Iba con nosotros un caballero amigo de mi papá, inglés también, un sportsman. Le había hablado a mi papá que quería casarse conmigo, como se hacía antes y como debe ser. (DONOSO, 1962:39)

Nótense en este extracto las marcas textuales que dan cuenta de la cosmovisión de la mujer y de por qué insta a la muchacha campesina a que se comporte de manera "decente", aludiendo a que en ese entonces la gente ha perdido los valores y las costumbres admisibles. Primero que todo, las personas calificadas como la "mejor gente" son aquellas que poseen joyas y vestimentas que denotan una alta posición social. Por otra parte, el hecho de tener un apellido foráneo -sobre todo inglés, como ella- es señal de estatus, ya que habían sido los capitales extranjeros los que de cierta manera habían desplazado a los propietarios de tierras que antes de la eclosión minera poseían el monopolio económico. Finalmente, las palabras de Elisita refieren a un tema de costumbres. JOCELYN-HOLT (1998) indica que ya en los años '50 se volvió habitual que se dieran matrimonios por amor y no por acuerdos económicos o de otra índole. A una persona que en la mitad del siglo XX era nonagenaria esto le habrá parecido una desviación del eje, una señal de libertinaje.

Misiá Elisa es sumamente católica y ha mentalizado a su nieto, criado por ella, acerca del pecado, el que cobra existencia incluso al solo concebir pensamientos tachables. Ella cree firmemente que por el hecho de no haberse entregado al placer, como lo hace Estela, está libre del infierno y puede considerarse santa sin reparos. Todo lo que ha sustentado su postura de vida está de capa caída y ha perdido vigencia junto con ella. El elemento que simboliza manifiestamente esta decadencia de su mundo es su casa. Las descripciones de esta, en las que Donoso se detiene extensamente, reflejan un lugar ajado, desteñido, en desuso. Los sillones cubiertos con sábanas y la loza lujosa guardada en cualquier lugar recóndito de la casa evidencian este ambiente físico, entre otros detalles:

La casa tenía un defecto: estaba orientada con tan poco acierto que la fachada recibía sol escasas horas [...]. En otra época era costumbre pintar la fachada todos los años cerca del dieciocho de septiembre, como asimismo los rosales, de blanco abajo y rojos en la punta. Pero rosales ya no iban quedando y todo envejecía muy descuidado. [...] ¡Qué se le iba a hacer! Los años pasaban y ya no valía la pena preocuparse. (DONOSO, 1962, p.13-14) 
Las memorias de la mujer fundadas en un pasado pleno de gloria denotan un contraste con su presente, despojado de vitalidad y corrompido irremediablemente según ella. También las visitas a la abuela han mermado progresivamente, porque la vigencia de este personaje ha desaparecido. Sin duda, la vejez de la mujer es un factor importante en su abandono; pero el estado de su espacio físico y los recuerdos de un pasado imponente y extraviado no responden a una cuestión etaria, sino que simbolizan la caída de un mundo conservador y elitista dentro del cual sus integrantes se sentían acreedores de una supremacía inapelable. Así, la anciana es el personaje que realmente encarna el problema abordado a partir de Coronación, que será recurrente en José Donoso.

Andrés, el nieto, por su parte, responde a otro perfil. Él no es un personaje propiamente decadente, por una razón fundamental: ateniéndonos al concepto de decadencia, vemos que en este está inserta la idea de menoscabo, de que algo ha dejado de ser lo que era y aquello que era estaba en condiciones más bien prósperas. Si intentamos encontrar ahora este rasgo en Andrés, no es posible ver en él un sujeto que responda a ese modelo. Las razones dicen relación con el problema del pasado. Decíamos que la abuela posee un ayer al que se aferra pues ve en este un esplendor que se ha opacado sin remedio. Pues el caso de Andrés es muy diferente, porque él no tiene recuerdos a los que recurrir para sustentar su monocorde presente.

El sujeto de Ábalos responde al hombre de aproximadamente la mitad del siglo XX que podía vivir de sus rentas, sin tener la necesidad de trabajar. Él ha estudiado leyes porque su familia esperaba eso de él, pero nunca ha conocido experiencias humanas tan simples como la motivación por algún oficio o el empeño en alguna actividad. Su mejor amigo -que en realidad es el único y que le hace compañía en gran medida por compasión-, llamado Carlos Gros, permanentemente le enrostra el hecho de haber dejado pasar la vida desde su abulia e impasibilidad. Llega a ser risible la manera en que este médico habla para referirse a la condición excesivamente flemática de su amigo: "El manual de Carreño, que parece haber sido la única influencia fuerte en tu vida, porque eso sí eres todo un caballero..." (DONOSO, 1962, p.73).

Andrés Ábalos es, entonces, un sujeto que no se ha construido una vida propia. Desde pequeño acarrea traumas sembrados por su abuela respecto a las aparentes perversiones que surgen ya en el pensamiento, mucho antes siquiera de concretarse en la acción. Esto lo ha hecho convertirse en un timorato y lo ha impulsado a resguardarse en el mundo del Club de La Unión y de Elisita, instancias en que no puede haber arrebatos de pasiones, 
soslayadas estas en todo momento por él. Sin embargo, a la edad de 54 años que el hombre tiene en la historia, ya no se le está haciendo soportable vivir días tan planos. Esta inquietud nace en él gatillada por la presencia de la joven sirvienta Estela, por quien se siente compulsivamente atraído. A partir del arribo de ella a su casa, todo lo que antes le producía una satisfacción sosa ahora derechamente le incomoda, como las conversaciones de los concurrentes al Club.

Todo este inmenso acontecimiento en su vida pone en jaque lo que para él era incuestionablemente de una sola manera, y empieza a sentirse aterrado por lo que en reiteradas ocasiones le ha criticado su único amigo: que él no ha vivido nada y se ha privado de todo lo placentero. Esto, unido a la inminente muerte de su abuela, lo hace verse en un abismo absoluto. Ahora quiere desordenar su vida, dejar de tener en su colección solamente diez bastones exactos.

Tal vez justamente como resultado de su educación católica castradora, él es un hombre escéptico: no ve la muerte más que como el fin. Y al tener un pasado sin contenido, no ve asidero alguno en su existencia y cae en la angustia total. Entonces se sume en pensamientos que lo ahogan cada vez de manera más insoportable: "Se vio, repentinamente, en el lecho de muerte, y tuvo el impulso salvaje de huir, de huir aullando de terror, de retroceder cincuenta años para vivirlo todo de nuevo y de otra manera" (Idem, ibidem, p.75).

La connotación angustiosa que posee la muerte se ha hecho para Andrés aun más aguda desde que conoce a Estela. Ella representa lo vivificante -ella y su amante-, y el contraste de esto con la palidez de los días del protagonista intensifica el sentido de la nada que lo empapa. De hecho, ella logra detonar lo poco de vida que hay en el hombre, lo que se hace notorio cuando él la ve con Mario besándose en una esquina y se sulfura de tal manera que por primera vez es enfático en algo: echa a Mario de su casa violentamente.

Posteriormente, Andrés Ábalos -al verse manipulado por Estela para complacer los propósitos de Mario y su hermano de robar en la casa de él- parece entregarse definitivamente a la locura, sobre la cual ya había reflexionado antes, vislumbrándola como única posibilidad legítima de vivir el mundo, porque en ella se aprecia lo realmente verdadero: el caos. GOIC (1971) identifica muy bien la sensación que experimenta el protagonista al entregarse a un estado de delirio que probablemente lo alivia: "tendrá una rara experiencia de la libertad" (175). Seguramente esta libertad es tal debido a que por fin Andrés se deja llevar por algo: primeramente, por su pasión hacia una jovencita; luego, por un camino de evasión que le quita el peso de su inanidad. 
Concluyamos, entonces, que el personaje protagónico de Coronación no responde efectivamente al retrato del sujeto decadente que a partir de esta novela será característico de la obra de José Donoso, por el hecho de que no tiene ninguna gloria pretérita que le haga sentir que algo ha dejado de ser. Mire hacia donde mire, el interior de Andrés no hace eco en ninguna parte: es simplemente un personaje vacuo, baldío y punto. Contrariamente, Elisita Grey representa el decaimiento de una clase social que ha conocido totalmente el esplendor y cuyos cimientos han quedado obsoletos debido a múltiples factores sociales, históricos y económicos. La cosmovisión que encarna la nonagenaria ha sucumbido y, encima, la condición decrépita que la consume acentúa este estado completamente alicaído. Andrés Âbalos es puramente la representación de lo anodino.

\section{El cine y la literatura}

El cine es un oficio joven en la historia de las artes, y desde que nació se ha visto envuelto en comparaciones con la literatura -específicamente con la novela-, las que en reiteradas ocasiones conllevan juicios de valor. Lo cierto es que, desde sus inicios, el cine ha adaptado grandes clásicos de la literatura, teniendo los realizadores diferentes conductas frente al acto de la adaptación, las que oscilan entre la fidelidad más absoluta al referente literario y la búsqueda de independencia respecto de este, guardando fidelidad solamente al argumento fundamental.

Ciertamente, tanto el cine de ficción como la narrativa son mayoritariamente géneros de acción. PEÑA-ARDID (1999) plantea que, como géneros de esta categoría, el cine de ficción y la narración literaria poseen dos ejes vinculantes: "suele admitirse que la configuración narrativa y el desarrollo argumental de una fábula serían elementos comunes y comparables entre el cine de ficción y la novela" (Idem, p.128).

Por otro lado, la literatura apela a todo un universo físico, el cual desemboca en forma de imágenes en la mente del lector, y que dice relación con el entorno de los personajes y con el aspecto de los lugares y sujetos. El cine es la única otra forma de arte que puede plasmar este universo de manera tal que pueda asimilarse a lo que se ha leído. Es la única otra manifestación artística que puede ofrecer acción en ilimitado desplazamiento. La técnica del travelling es un ejemplo claro de ello, debido a que el seguimiento que hace la cámara respecto de un personaje es a lo largo de un espacio amplio. Uun caso paradigmático de un filme inspirado en la 
literatura en que ocurre algo así es Fahrenheit 451, de 1966, de François Truffaut, inspirado en la novela homónima de Ray Bradbury, de 1953. En el relato literario, el protagonista escapa de sus perseguidores y corre hasta llegar a una zona en medio de la naturaleza en la cual se refugian algunos sujetos que quieren conservar la literatura de manera oral. Ciertamente, esta secuencia sólo podría haber sido trasladada de manera óptima al formato cinematográfico, en que el movimiento de cámara permite recrear un pasaje literario de las características descritas.

Es importante considerar asimismo que en la gestación de una película se encuentran cimientos literarios. Toda obra de arte habitualmente se explica a través del lenguaje verbal, pero en el cine particularmente subyace un esqueleto que es el guión literario. Por ello, es natural que un realizador pueda vislumbrar en una obra literaria el guión de su futura película en estado de latencia. Los filmes pueden ser narrados verbalmente bajo la misma lógica con que puede ser resumida una novela, o sea, sintetizando la historia en función de contar los núcleos que la configuran y que forman, muchas veces - Raúl Ruiz probablemente lo negaría a partir de su teoría del conflicto central ${ }^{2}$-, un gran sintagma.

Así como las que hasta ahora se han indicado y expuesto, muchas otras explicaciones pueden ofrecer señales acerca de por qué el cine ha estado siempre manteniendo vínculos con la literatura, o por qué algunos directores, como Stanley Kubrick, han dedicado su carrera a hacer cine en base al trabajo de adaptar novelas.

Es necesario apuntar lo siguiente: la literatura es también portadora de potencialidades que ofrecen dificultades al cine a la hora del ejercicio de adecuación de un argumento literario al formato audiovisual. Si bien el cine puede ocuparse sin mayor problema del entorno de los personajes, no le resulta tan fácil hacerlo cuando se trata del mundo interno de un sujeto. Esto es algo en que la literatura puede ocupar las páginas que le sean necesarias y para lo que puede valerse de recursos que le son propios, como por ejemplo el monólogo interior y el estilo indirecto libre. En la medida en que el relato está más centrado en lo que deviene en la mente del personaje, menos manejable resulta para un cineasta que pretenda adaptarlo. GIMFERRER (1985) postula esta idea refiriéndose a la novela contemporánea:

Joyce y Proust, en efecto, señalan el comienzo de la novela contemporánea en forma definitivamente cristalizada, $y$, por lo mismo, la aparición de sus novelas capitales marca el

2 Ver RUIZ, Raúl. Poética del cine. Santiago de Chile: Sudamericana, 2000. 
gozne a partir del cual, ineluctablemente, la narrativa contemporánea irá avanzando hacia la inadaptabilidad fílmica. (Idem, p.83)

Claramente, hay directores de cine que no se amilanan frente a una obra que presente un carácter psicológico marcado. Es el caso del ya mencionado realizador chileno Raúl Ruiz, quien se propuso adaptar, de Marcel Proust, El tiempo recobrado (1927), último tomo de En busca del tiempo perdido, en su filme homónimo de 1999. Mediante diversas técnicas, el cineasta logra darle a su filme un énfasis en el discurrir mental del protagonista.

El caso recién citado es ejemplar dentro del cine, sin embargo, lo más frecuente es que la adaptación de novelas o cuentos se haga a partir de historias que ofrecen un fuerte desarrollo de eventos que suceden en el mundo extra-mental del sujeto protagónico. La narrativa es rica en posibilidades de desarrollo de aspectos internos de los personajes; se sirve ilimitadamente de la palabra, su instrumento. El cine posee una condición que lo hace ser más directo, y esto se traduce en que no le es imprescindible un narrador. El espectador puede asistir a un rostro angustiado y notar esta sensación sin que sea necesario que se diga nada. En ese sentido, destaquemos que el cine expresionista hizo del entorno una prolongación de la sensación del personaje.

Respecto a las contribuciones que puede ofrecerle el cine a la literatura, es importante partir señalando que tanto reputados teóricos como cineastas que han teorizado sobre su oficio coinciden en que una adaptación no debería procurar apegarse a la obra literaria. CARMONA (1996) es muy certero en su explicación sobre el error en que incurren algunos cineastas en su conducta mimética respecto al relato literario que adaptan: "El carácter fallido de algunas adaptaciones literarias estribaría, sustancialmente, en el abandono de las sugerencias poéticas que toda narración encierra, dejándose llevar por dicha ilusión mimética" (Idem, p.220). Se puede afirmar, entonces, que lo óptimo es que un filme reelabore la historia a partir del argumento que ella le proporciona, que reorganice ese material y lo refiera sirviéndose de los medios que le son propios. Es de suponer que si un cineasta se interesa por llevar a la pantalla determinada obra literaria es porque se ha sentido atraído no solo por el argumento de esta, sino también por lo que el relato deja entrever. Las "sugerencias poéticas" que contiene una obra literaria pueden ser asidas y enriquecidas por el cineasta mediante recursos propios de la cinematografía, los que no necesariamente encuentran su referente análogo en el género narrativo. El cine puede mostrar perspectivas que en el cuento o la novela no han sido tratadas o enfatizadas. 
Partamos refiriéndonos al punto de vista. La cámara, como "aparato enunciativo", puede ser empleada por el director con infinitos propósitos que estén al servicio de hacer más rica la narración. Por ejemplo, puede funcionar como "cámara subjetiva" en un filme de suspenso, cuando el protagonista va siendo perseguido desde un enfoque tal que el espectador ve como si fuera él mismo el perseguidor, como sucede en la secuencia más tensa de The Silence of the Lambs (Jonathan Demme, 1991). El punto de vista en el cine es un enfoque efectivo. PEÑA-ARDID (1999) entrega una explicación muy clara a este respecto:

El concepto de "punto de vista" en el cine, a diferencia de la novela, tiene al menos un primer sentido no metafórico; antes que nada es, literalmente, un "punto de vista óptico", el lugar de emplazamiento de la cámara desde el que se mira -y se da a ver- un objeto dado. (Idem, p.143)

El aparato de la cámara tiene peso en el énfasis de los sentimientos. Por ejemplo, un primerísimo primer plano de un sujeto llorando genera en el espectador sensaciones sumamente intensas. Si a esto agregamos el carácter auditivo del cine, queda aun más claro cuánto poder semántico puede sumar una película a una historia literaria.

El cine, además de narrar, representa. A esto se debe el hecho de que un personaje pueda decir algo y a la vez desmentirlo mediante una acción. Dentro de esta representación, en la cinematografía surgen construcciones narrativas que le son propias y que no pueden parangonarse con las construcciones narrativas connaturales a la literatura. Por el hecho de que la cámara encuadra, existe todo un mundo en la película que puede clasificarse como extra-visual, que pertenece al fuera de campo. El personaje puede estar mirando hacia un punto que está fuera del campo visual del espectador, pudiendo con ello generar un ambiente de incertidumbre respecto de lo que está aconteciendo. Este es un recurso utilizado en las películas de suspenso o terror y respecto al cual la literatura de terror no posee alguna técnica realmente equiparable.

Lo que ha sido descrito en el párrafo anterior está vinculado con el carácter icónico que el cine posee. Además de esta condición que le es inherente, el hecho de que este opere con tecnología también implica una serie de aportaciones a las posibilidades que existen para narrar una historia. Por ejemplo, el acelerado y el ralentí son efectos que brindan absoluta riqueza a una escena literaria que está buscando ser representada en la pantalla. Si una madre salva a su hijo de ser atropellado en un relato literario 
determinado, dependerá de la aptitud del escritor cuánta intensidad pueda imprimirle a ese pasaje de su historia. Sin embargo, un buen manejo de la cámara lenta en un pasaje de tales características en el cine puede generar efectos que difícilmente dejarán a un espectador impávido. Sobre un evento como el descrito, resulta más fácil suponer los efectos que este puede causar en el espectador que en el lector. Esto se relaciona con que el cine, al presentar una imagen en movimiento y sonora, opera de un modo parecido a la realidad; y por ello puede generar efectos en cierta medida más predecibles en el receptor que la literatura. En esta última hay tantas imágenes y sonidos como sujetos que leen. Pero el cine, si recurre, por ejemplo, a una melodía muy triste en una escena de desconsuelo, puede apostar con mayor certeza al sentimiento que despertará en quien ve y escucha.

El hecho de que al lenguaje verbal le sea más fácil jugar con la ambigüedad se debe a que cada palabra es un símbolo; en cambio, la imagen y el sonido, si bien pueden simbolizar algo, no son un símbolo en sí mismos. Es interesante verificar lo afirmado a través de las palabras de un propio cineasta, ANDREI TARKOVSKI (1984): "La recepción de una obra literaria se realiza exclusivamente a través de un símbolo, de un concepto, tal como es presentado por la palabra. El cine [...], por el contrario, ofrece la posibilidad de una recepción inmediata..." (Idem, p. 204).

Ese carácter directo que es inherente a la condición de lo audiovisual hace del cine una manifestación cultural de códigos más fácilmente captables. Un libro nunca será mejor leído que en su idioma de origen. Una imagen alcanza lo universal y un sonido también, aunque esto tenga aristas discutibles.

En síntesis, una película puede vigorizar el argumento de una historia literaria, ya que una imagen y un sonido pueden echar mano de recursos completamente distintos a los de las letras. Por otra parte, la capacidad del director para interpretar las "sugerencias poéticas" apuntadas por Carmona y para operar lúcidamente con las posibilidades que el lenguaje cinematográfico encierra, es el factor fundamental para que el filme resulte una obra significativa y autónoma, y no un mero traspaso literal de la historia escrita en el libro a un formato audiovisual.

\section{Coronación de Silvio Caiozzi: el énfasis en lo visual}

Esta película del renombrado cineasta chileno es del año 2000, por ende, muy alejada del momento en que la novela fue concebida. Fundamental es 
señalar que Caiozzi ha sido siempre un admirador de José Donoso, con el cual incluso escribieron guiones en conjunto, como ocurrió en el filme La luna en el espejo, de 1990. El realizador tiene trayectoria como director de fotografía, habiendo trabajado, por ejemplo, con creadores como el ya citado Raúl Ruiz en su periodo chileno, en Palomita Blanca, de 1973, filme censurado por la dictadura.

Caiozzi es el caso de un cineasta motivado permanentemente por la literatura, y, específicamente, por las narraciones donosianas. De hecho, Mónica Villarroel en su estudio sobre el cine chileno, titula el apartado sobre el realizador chileno con el nombre de "El universo de Donoso". Lo que principalmente le interesa a Caiozzi de las historias del afamado escritor es el ambiente de menoscabo con que este impregna sus libros: "Es un universo de atmósferas, de deterioro, de personajes que están al borde de. [...] Siempre se está terminando algo: una raza, una sociedad o un personaje" (CAIOZZI apud VILLARROEL 2005:54).

Este interés por plasmar el ambiente decaído de las historias de Donoso ya había sido enfocado en una película de Caiozzi, La luna en el espejo (en la que trabajó el escritor como guionista, como ya se mencionó), respecto a la cual el Premio Nacional chileno manifiesta que está presente la historia de Coronación sin ser propiamente una adaptación de la novela: "La historia de esta película es la historia de Coronación mirada desde otro punto de vista. Es la simbología de casi todas mis novelas: el espacio cerrado, el departamento, la persona que deforma la realidad, el enfermo y lo que viene a deshacer el orden preestablecido..." (DONOSO apud VILLARROEL, 54)

Es fundamental no desconocer estos antecedentes para tener en consideración la trayectoria que tiene Silvio Caiozzi en relación con Donoso. Este recorrido juntos es justamente lo que le da peso a la película del año 2000, pues en ella se aprecia el conocimiento que tiene el cineasta sobre todo de las atmósferas de caducidad y de claustro que son propias del escritor.

Si nos introducimos ya en el trabajo que hace el realizador a partir de la clásica novela de 1957, lo primero que se debe señalar es que es patente la fuerza que tiene lo visual en el filme, como en todos sus trabajos, en coherencia con su trayectoria como director de fotografía. El universo extra-verbal es tratado con maestría por él.

Partamos por el personaje de Andrés. Para encarnar a este sujeto, el director buscó un actor que pudiera representar fácilmente una actitud un tanto patética primero que todo a partir de su aspecto físico. Julio Jung, en el rol protagónico, es indudablemente un hombre cuyo rostro despierta 
emociones, ya que es una cara fuertemente expresiva y con matices grotescos surgidos de sus rasgos marcadamente grandes. Además, el actor sabe ir dotando su rostro de un progresivo deterioro en la medida en que el filme avanza y que su pasión por Estela lo va consumiendo. Al final, el aspecto de Andrés llega a asquear, y el espectador se compenetra de la repulsión de la muchacha cuando el hombre, ávido, la intenta besar en mitad del robo que busca concretar su novio con el hermano.

Ahora pensemos en la casa. Sabemos que el caserón de los Ábalos es un factor determinante en el ambiente decadente que Donoso le imprime a su historia. En ella, el narrador omnisciente se detiene a describir el lugar con detalle y contrastando el estado actual que tiene con la gloria que poseyó. Por ello, los muebles están tapados con sábanas, el jardinero ya no acude a hacer labores de ornato y ni siquiera se hace necesario sacar la maleza del patio. A este elemento de la casa, Caiozzi le saca provecho absolutamente. El enfoque del espacio con la cámara desde variadas posiciones es permanente y es el recurso del que se sirve el director en lugar de hacer uso de lo verbal, sacando provecho, así, del carácter directo que el cine posee. Caiozzi pone al espectador en frente de la decadencia de la casa desde variados puntos de vista, adquiriendo esta una presencia marcada en la sensación de ruina que se percibe en el filme.

Se ha indicado en páginas anteriores que en la literatura se puede hacer uso ilimitado del verbo para referir a la psiquis de un personaje y también para dar rienda suelta a la descripción de lugares. Se ha aclarado, también, que en el cine esto no sucede de igual manera. Sin embargo, bien se puede recurrir a algunos parlamentos para dar cuenta de cómo es algo o de qué siente algún sujeto. Pero para el cineasta chileno esto no es necesario, porque a partir de lo visual plasma todo lo penoso de la sensación de Andrés y del decaimiento de la casa. Es la cámara la que se encarga de presentar el clima de la historia de Coronación. Lo que los personajes dicen se subordina al poder de la visualidad en el filme.

Ha sido señalado que para una película es más fácil adaptar una historia literaria en que los hechos tienen supremacía. Pues Caiozzi se arriesga un poco y adapta una novela en que el decurso de los pensamientos fatalistas de un sujeto opaco es muy relevante, en conjunto con la mostración de un personaje -la abuela- que ejemplifica la caída irremediable de una clase poderosa. Solamente en dos ocasiones abre el cineasta diálogos entre Andrés y su amigo Carlos, sin darles un espacio mayor que el estrictamente necesario.

La irrupción de los traumas de Andrés a partir de su estricta educación católica, que lo ha vuelto culposo, es tratada de un modo equivalente a 
como sucede en el surrealismo de Luis Buñuel: yuxtaponiendo los traumas de infancia, las culpas morales, a los momentos presentes del personaje. Podemos ver un ejemplo de lo referido en el filme Belle de jour, de Buñuel, de 1966, en que las secuelas de la educación cristiana castradora surgen en medio de escenas que corresponden al presente de la protagonista, encarnada por Catherine Deneuve, sin cambios de tonalidad ni fundidos en negro ni ningún tipo de estrategia narrativa que haga ver al espectador de forma obvia que estamos frente a un estado de conciencia distinto del normal en el personaje. Igual cosa sucede en Coronación, cuando la narración nos sitúa frente a los traumas culposos de Andrés. Esto responde a un modo de enfatizar en lo visual y aminorar la carga verbal del filme. Esta estrategia implica un receptor más atento que aquel que supone un filme que todo lo verbaliza, echando mano de lo explícito para asegurarse la captación del mensaje.

El abundante uso del estilo indirecto libre que está presente en la novela es trocado acá por el énfasis en la mirada, en el aspecto físico anodino, en el rostro demacrado y en la correspondencia del sujeto de Andrés con los objetos que lo rodean. Y también se materializa la añoranza de un pasado glorioso por parte de la abuela en imágenes diversas. Muy representativa es la escena en que la anciana mira por la ventana recordando la magnificencia de sus tiempos lejanos con un rostro felizmente nostálgico, y aparece ante nuestros ojos, en cámara subjetiva, la vista del patio desde su dormitorio, en que este se ve deslucido; entonces, el mustio espacio cambia y da lugar a su esplendor de antaño, incorporando la ilusión de la anciana a la imagen; pero luego, al encaramarse más, esta se estrella contra la realidad del jardín, la cual desfigura su rostro con una mueca de decepción. La escena descrita, que no tiene presencia de lo verbal, cobra aun mayor fuerza gracias a la actuación de María Canepa, actriz de rostro profundamente expresivo.

Según hemos ido observando, la formación como director de fotografía de Silvio Caiozzi se hace evidente en Coronación, así como se filtra en todos sus filmes. Lo más importante para el cineasta es que en la expresión de los personajes y en el aspecto de los lugares radique el poder semántico de la historia.

Caiozzi lee en Donoso ese ambiente deteriorado que es señal de un menoscabo más profundo aun, resultado de la caída del poder de una clase. Y aquellas "sugerencias poéticas" - toda aquella crítica, quizás solapada, a la cultura cristiana castradora y dominante en Chile, asentada en las clases altas; y toda la ruina de esta cultura a la luz de la contemporaneidad- son interpretadas de un modo acertado por Caiozzi, lo que resulta así además porque el cineasta conoce bien al escritor. 
Ambos creadores saben imprimir en sus historias atmósferas marcadas y esto les da una identidad notoria dentro de la cultura chilena. Donoso es probablemente de los narradores más afamados de ese país, figura del boom latinoamericano allí; y Caiozzi, por su parte, es un realizador indudablemente representativo de la historia del cine de aquel país sudamericano (su filme Julio comienza en julio, de 1976, estrenado en 1979, fue elegido como el mejor filme chileno del siglo XX), marcado por la permanente referencia a la literatura.

\section{REFERENCIAS}

CARMONA, Ramón. Cómo se comenta un texto fílmico. Madrid: Cátedra, 1996.

DONOSO, José. Coronación (segunda edición). Santiago de Chile: ZigZag, 1962.

GIMFERRER, Pere. Cine y literatura. Barcelona: Planeta, 1985

GOIC, Cedomil. La novela chilena. Los mitos degradados (tercera edición). Santiago: Universitaria, 1971

JOCELYN-HOLT, Alfredo. El Chile perplejo. Del avanzar sin transar al transar sin parar. Santiago: Planeta, 1998.

PEÑA-ARDID, Carmen. Literatura y cine, una aproximación comparativa. Madrid: Cátedra, 1999.

VILLARROEL, Mónica. La voz de los cineastas. Cine e identidad chilena en el umbral del milenio. Santiago de Chile: Cuarto Propio, 2005.

Recebido em: 15/06/2016. Aceito em: 07/09/2016. 